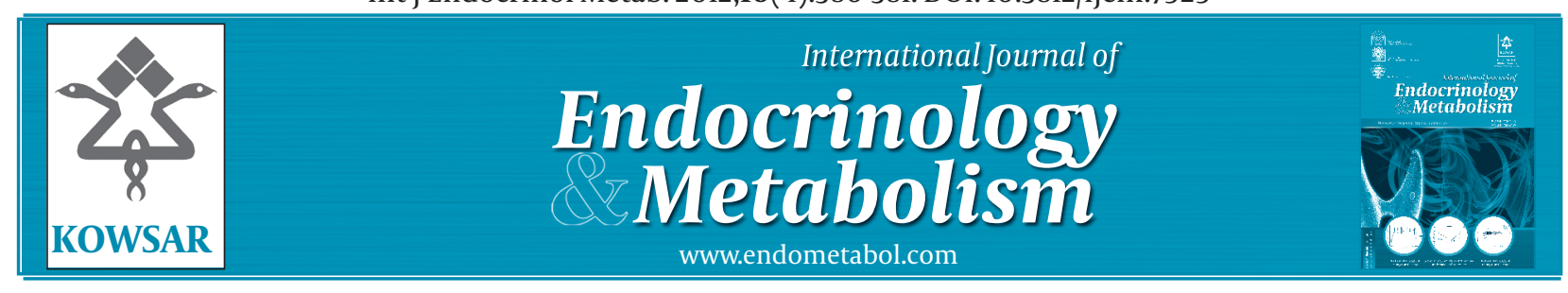

\title{
Obesity Dilemma: Are There Enough Bariatric Surgeons?
}

\author{
Fereidoun Azizi ${ }^{*}$ \\ ${ }^{1}$ Endocrine Research Center, Research Institute for Endocrine Sciences, Shahid Beheshti University of Medical Sciences, Tehran, IR Iran
}

A R T I C L E I N F O

Article type:

Editorial

\section{Article history:}

Received: 26 Aug 2012

Revised: 30 Aug 2012

Accepted: 06 Sep 2012

\section{Keywords:}

Obesity

Diabetes Mellituss Type2

The $21^{\text {st }}$ century epidemics of obesity and diabetes emphasize the need for an effective range of treatment option for management of these health care crisis (1).

Lack of long-term success with dieting and limited medical pharmacologic options denotes that the current medical treatment options of obesity and diabetes are far-reaching the goals of appropriate management (2) in last 2 decades, bariatric surgery has shown to be the most effective treatment for morbid obesity and diabetes in individuals with BMI $\geq 35 \mathrm{~kg} / \mathrm{m} 2$ (3). Bariatric surgery is associated with substantial and durable weight loss and favorable metabolic effects far beyond those achieved by lifestyle modifications and pharmacological treatments, resulting in impressive reduction in comorbidant of obesity and diabetes, along with increase in longevity (4-7).

Coinideal increases in the prevelence of diabetes and obesity are issues of major concern, More than $60 \%$ of diabetics are obese and treatment of the combination of obesity and type 2 diabetes (diabesity) is now a public health priority (8). As much as $78 \%$ of diabetic patients have had complete resolution and $62 \%$ have remained in
- Implication for health policy/practice/research/medical education:

Baratric surgery has shown to be the most effective treatment for morbid obesity and obese diabetics. However the number of surgeons for all the operations indicated are not achievable.

- Please cite this paper as:

Fereidoun Azizi. Obesity Dilemma: Are There Enough Bariatric Surgeons? Int J Endocrinol Metab. 2012;10(4):580-1. DOI: 10.5812/ ijem.7929

Published by Kowsar Corp, 2012. cc 3.0.

remission more than 2 years after bariatric operation (9). There are only 2 prospective randomized controlled trials in regard to bariatric surgery in diabetics. One showed $73 \%$ remission of diabetes in those who received surgery, compared to $13 \%$ in control group. Another randomized study showed that proportion of patients with a glycated hemoglobin level of $6 \%$ or less after 12 months of intervention was $12 \%$ following intensive medical therapy, $42 \%$ after gastric bypass and 37\% following sleeve gastrectomy (10). Although improvement and resolution of diabetes is mostly related to weight loss after surgery, the incretin system may also have some important role. Plasma concentration of incretin hormones increases and insulin secretion and glucose tolerance improve after operation; equivalent weight loss by diet does not induce above changes (11).

Considering all of the above, bariatric surgery has emerged as an impressive treatment of obesity and type 2 diabetes. It has rapidly evolved over the last 30 years and current procedures are effective, safe, less invasive, and cost effective (12). The 1991 National Institutes of Health

\footnotetext{
* Corresponding author: Fereidoun Azizi, Research Institute for Endocrine Sciences, Shahid Beheshti University of Medical Sciences, P.O. Box:19395-4763, Tehran, IR Iran, Tel:+98-2122409309, Fax:+98-2122402463, E-mail: azizi@endocrine.ac.ir 
statement indicated that all obese patients with BMI > $40 \mathrm{~kg} / \mathrm{m} 2$ and those with a BMI 35-40 kg/m2 with significant comorbidities interfering with their lifestyles, were candidates for surgical treatment (13). This statement has become the most generally accepted guideline for determining indications for bariatric surgery. As experience with surgical operations for obesity increased, few medical societies have broadened indications to include patients with BMI $30-34 \mathrm{~kg} / \mathrm{m} 2$ with a comorbid condition that can be cured or improved by substantial weight loss (14).

Universal surgical treatment of obesity is not achievable with the world's current health care and surgical resources. The estimation is that it would take 5500 surgeons doing 400 cases a year, each for 10 years, to attempt bariatric surgery for every 22 million obese Americans (15). In Iran, there are approximately 40 million, aged $\geq 20$ years and the rates of $\mathrm{BMI}>40$ and $35-40 \mathrm{~kg} / \mathrm{m} 2$ in this age group are 1.3 and $3.8 \%$, respectively (16). Therefore, 520,000 subjects with $\mathrm{BMI}>40 \mathrm{~kg} / \mathrm{m} 2$ and 106400 type 2 diabetic patients with BMI between 35-40 require obesity operations. It may be estimated that 157 bariatric surgeons would need to do 400 cases a year, each for 10 years, to perform surgical treatment for 626400 obese Iranians. Another estimation for Tehran with its 12 million population, shows that $1.66 \%$ of people $\geq 20$ years of age, have BMI $>40 \mathrm{~kg} / \mathrm{m} 2$ (17) and another $0.69 \%$ have diabetes and BMI of $30-40 \mathrm{~kg} /$ $\mathrm{m} 2$ (18); hence a total of $2.35 \%$ of Tehranian population $\geq$ aged 20 years have indications for bariatric surgery. Extrapolating these data to $7,800,000$ Tehranians $\geq 20$ years of age, indicates that 183,300 obese subjects may require bariatric surgery. It may then be estimated that 46 surgeons should perform 400 cases a year each for 10 years to provide surgical treatment for all obese Tehranians.

Therefore, data available indicate that bariatric surgery cannot provide the impact necessary for reduction in health care and economic costs worldwide, neither in the developed, nor in developing countries. The numbers of surgeons needed for all the operations indicated are not achievable, in particular for many developing countries, suffering from epidemics of diabesity.

It is the opinion of this editorial that although bariatric surgery is a good addition to management of patients with obesity and diabetes, the crisis caused by the rise in the prevalence of these conditions, must be addressed by more comprehensive and long-term, concerted policy efforts worldwide. Healthy eating, regulation of food sup- ply, public education, healthy commuting through walking or biking and other means of lifestyle change need political commitment for infrastructural changes and incentives for effective research into novel and effective nonsurgical treatments for obesity and type 2 diabetes.

\section{References}

1. World Health Organization. Overweight and obesity. Fact sheet No. 311. World Health Organization, Geneva (Switzerland). 2006.

2. Dushay J, Gao C, Gopalakrishnan GS, Crawley M, Mitten EK, Wilker E, et al. Short-term exenatide treatment leads to significant weight loss in a subset of obese women without diabetes. Diabetes Care. 2012;35(1):4-11.

3. Eldar S, Heneghan HM, Brethauer SA, Schauer PR. Bariatric surgery for treatment of obesity. Int J Obes (Lond). 2011;35 Suppl 3:S16-21.

4. Buchwald H, Oien DM. Metabolic/bariatric surgery worldwide 2008. Obes surg. 2009;19(12):1605-11.

5. Dumon KR, Murayama KM. Bariatric surgery outcomes. Surgl clin NAm. 2011;91(6):1313.

6. Sjostrom L, Narbro K, Sjostrom CD, Karason K, Larsson B, Wedel $\mathrm{H}$, et al. Effects of bariatric surgery on mortality in Swedish obese subjects. N Engl J Med. 2007;357(8):741-52.

7. Terranova L, Busetto L, Vestri A, Zappa MA. Bariatric surgery: costeffectiveness and budget impact. Obes Surg. 2012;22(4):646-53.

8. Dixon JB, le Roux CW, Rubino F, Zimmet P. Bariatric surgery for type 2 diabetes. The Lancet. 2012;379(9833):2300-11.

9. Buchwald H, Estok R, Fahrbach K, Banel D, Jensen MD, Pories WJ, et al. Weight and type 2 diabetes after bariatric surgery: systematic review and meta-analysis. Am J Med.2009;122(3):248-56 e5.

10. Dixon JB, O'Brien PE, Playfair J, Chapman L, Schachter LM, Skinner $\mathrm{S}$, et al. Adjustable gastric banding and conventional therapy for type 2 diabetes: a randomized controlled trial. JAMA. 2008;299(3):316-23.

11. Laferrere B. Diabetes remission after bariatric surgery: is it just the incretins? Int J Obes (Lond). 2011;35 Suppl 3:S22-5.

12. Elder KA, Wolfe BM. Bariatric surgery: a review of procedures and outcomes. Gastroenterology. 2007;132(6):2253-71.

13. Gastrointestinal surgery for severe obesity. Consens Statement. 1991;9(1):1-20

14. Buchwald H. Consensus conference statement bariatric surgery for morbid obesity: health implications for patients, health professionals, and third-party payers. Surg Obes Relat Dis. 2005;1(3):371-81.

15. Richards NG, Beekley AC, Tichansky DS. The economic costs of obesity and the impact of bariatric surgery. Surg Clin North Am. 2011;91(6):1173-80, vii-viii.

16. Esteghamati A, Khalilzadeh O, Mohammad K, Meysamie A, Rashidi A, Kamgar M, et al. Secular trends of obesity in Iran between 1999 and 2007: National Surveys of Risk Factors of Non-communicable Diseases. Metab Syndr Relat Disord. 2010;8(3):209-13.

17. Hosseinpanah F, Barzin M, Eskandary PS, Mirmiran P, Azizi F Trends of obesity and abdominal obesity in Tehranian adults: a cohort study. BMC Public Health. 2009;9:426.

18. Harati H, Hadaegh F, Momenan AA, Ghanei L, Bozorgmanesh MR, Ghanbarian A, et al. Reduction in incidence of type 2 diabetes by lifestyle intervention in a middle eastern community. Am J Prev Med. 2010;38(6):628-36 e1. 